\title{
High calcium intake from fat-free milk, body composition and glycaemic control in adults with type 2 diabetes: a randomised crossover clinical trial
}

\author{
Júnia Maria Geraldo Gomes ${ }^{1}$, Jorge de Assis Costa $^{2}$, Priscila Vaz de Melo Ribeiro ${ }^{2 *}$ and \\ Rita de Cássia Gonçalves Alfenas ${ }^{2}$ \\ ${ }^{1}$ Instituto Federal do Sudeste de Minas Gerais - Campus Barbacena, Rua Monsenhor José Augusto, 204, Bairro São José, \\ Barbacena, Minas Gerais CEP 36205-018, Brazil \\ ${ }^{2}$ Departamento de Nutrição e Saúde, Universidade Federal de Viçosa, Avenida PH Rolfs, s/n, Viçosa, Minas Gerais CEP \\ 36570-000, Brazil
}

(Submitted 12 February 2019 - Final revision received 30 April 2019 - Accepted 7 May 2019; First published online 1 August 2019)

\section{Abstract}

We evaluated the effects of high-Ca fat-free milk $v$. low-Ca control diet on adiposity and on glycaemic control. Fourteen subjects with type 2 diabetes (aged 49.5 (SD 8.6) years, BMI 29.4 (SD 4.5) kg/m², low habitual Ca consumption ( $<600 \mathrm{mg} / \mathrm{d}$ )) were included in this randomised, crossover clinical trial. Subjects participated in two 12-week experimental sessions (high-Ca fat-free milk (HC) or low-Ca control (LC)) separated by 8-week washout. Subjects daily consumed in the laboratory a breakfast shake containing $700 \mathrm{mg}$ (HC) or 6.4 mg (LC) of Ca. Energy-restricted diets containing $800 \mathrm{mg}$ of dietary $\mathrm{Ca} / \mathrm{d}$ were prescribed. Dietary records data indicated the consumption of $1200 \mathrm{mg}$ of $\mathrm{Ca} / \mathrm{d}$ during $\mathrm{HC}$ and of $525 \mathrm{mg}$ of $\mathrm{Ca} / \mathrm{d}$ during LC. There was a greater reduction in body weight, body fat mass, waist circumference and waist:hip ratio after HC. Serum 25-hydoxyvitamin D and homeostatic model assessment-2 $\beta$-cell function (HOMA2-\%B) increased, and serum uric acid, parathormone (PTH) and glycated $\mathrm{Hb}(\mathrm{HbA1c})$ concentrations reduced after $\mathrm{HC}$. In addition, changes from baseline in terms of serum uric acid, glucose, HbA1c and PTH concentrations were lower, and those of HOMA2-\%B, serum Ca and 25-hydoxyvitamin D were higher after the HC than after LC. The consumption of approximately three servings of fat-free milk and $1200 \mathrm{mg}$ of dietary $\mathrm{Ca} / \mathrm{d}$ enhanced weight loss, improved body composition and promoted glycaemic control in subjects with type 2 diabetes and low habitual Ca consumption $(<600 \mathrm{mg} / \mathrm{d})$.

Key words: Body composition: Calcium: Dairy products: Diabetes: Obesity

Although dietary intervention has been recognised as useful in the treatment of type 2 diabetes mellitus (T2DM), current guidelines emphasise the role of macronutrients in glycaemic control in T2DM patients, giving little attention to micronutrients ${ }^{(1)}$. The benefits of dietary Ca and dairy products to control T2DM have been suggested ${ }^{(2-4)}$.

Adequate Ca consumption seems to improve glucose homeostasis in adults with T2DM, particularly among low habitual consumers $(<600 \mathrm{mg} / \mathrm{d})^{(2)}$. That effect seems to be mainly due to the consumption of fat-free dairy products ${ }^{(5)}$ associated with energyrestricted diets ${ }^{(6)}$. A meta-analysis of randomised clinical trials indicated that increasing dairy product intake resulted in greater body weight (BW) and body fat losses, while lean mass loss was attenuated in subjects on weight loss diets ${ }^{(7)}$. However, the effect of different dairy sources could not be distinguished (e.g. milk $v$. cheese $v$. yoghurt ${ }^{(7)}$.
The effects of dairy components on BW and body composition in athletes and healthy overweight and obese adults have been extensively investigated ${ }^{(8-19)}$. However, few studies have examined the effect of dairy foods on individuals with $\mathrm{T}_{2} \mathrm{DM}^{(2,4)}$. Clinical evidences described in a systematic review indicated that dairy foods and dairy proteins (mainly whey protein) consumption might improve insulin secretion in T2DM adults $^{(4)}$. However, due to the different doses consumed, different dairy sources, and the short-term nature of the clinical trials it is difficult for us to make effective dietary recommendations based on the results obtained in the studies included in that review $^{(4)}$.

Considering the relevance of glycaemic control to prevent T2DM complications and the scarcity of well-controlled studies concerning the role of dairy products and $\mathrm{Ca}$ consumption in T2DM, we compared the effects of low-Ca and high-Ca fat-free

Abbreviations: BW, body weight; FM, fat mass; HbA1c, glycated Hb; HC, high-Ca fat-free milk; HOMA2-\%B, homeostatic model assessment-2 $\beta$-cell function; IR, insulin resistance; LC, low-Ca control; PAL, physical activity level; PTH, parathormone; T2DM, type 2 diabetes mellitus.

* Corresponding author: P. V. M. Ribeiro, fax +55 31 38992541, email priscilavazdemelo@yahoo.com.br 
milk consumption on obesity and glycaemic control in subjects with T2DM.

\section{Subjects and methods \\ Subjects}

Eligible subjects were adults of both sexes with T2DM, treated with only diet or with diet plus oral hypoglycaemic agent (Metformin), that had the metabolic syndrome ${ }^{(20)}$, had low habitual Ca intake ( $<600 \mathrm{mg} / \mathrm{d}$ ), were between 20 and 59 years of age, had a dietary restraint $<14^{(21)}$, had a light to moderate physical activity level (PAL) ${ }^{(22)}$ and had T2DM for at least 1 year. Exclusion criteria were (1) smokers; (2) use of Ca, vitamin D, Zn or $\mathrm{Mg}$ supplements or medication that affects the metabolism of these micronutrients; (3) use of drugs (except hypoglycaemic drugs), herbs or diets for weight loss; (4) hormone replacement therapy; (5) menopause or in post-menopause; (6) recent weight gain or loss $( \pm 5 \mathrm{~kg}$ ) over the previous 3 months; (7) recent change in PAL over the previous 3 months; (8) aversion or intolerance to the shakes provided during the study; (9) consumption of more than $12 \mathrm{~g}$ of alcohol/d for women and $24 \mathrm{~g} / \mathrm{d}$ for men; (10) eating disorders; (11) endocrine (except T2DM and obesity), kidney or liver pathology; (12) Ca malabsorption; (13) history of recurrent nephrolithiasis; (14) history of gastric surgery or current gastric disease including gastroparesis; (15) consumption of more than $350 \mathrm{mg}$ of caffeine/d; (16) pregnancy or lactation; (17) anaemia; and (18) changes in the medication type or dosage during the study. Sample size was calculated according to Mera et $a l .{ }^{(23)}$, considering the glycated $\mathrm{Hb}$ (HbA1c) as the main variable. Our eligible subjects' baseline mean and standard deviation HbA1c values were applied, considering a desirable reduction of $1 \%$ to decrease microangiopathy and neuropathy occurrence ${ }^{(1)}$. The statistical power was set up at $90 \%$. Therefore, and by applying a $P$ value $<0.05$, the sample size required in our study was equivalent to fourteen volunteers per session. Four men and ten women completed the study (49.5 (sD 8.6) years old, and BMI of 29.4 (SD 4.5$) \mathrm{kg} / \mathrm{m}^{2}$ ).

The study protocol was approved by the ethics committees of the Federal University of Viçosa, Brazil. All subjects provided their fully informed and written consent before participation.

\section{Study design}

Details of the present study design were described previously ${ }^{(24)}$. In short, subjects completed a randomised double-blinded, crossover clinical trial of two 12-week sessions separated by a washout period of 8 weeks. Subjects were initially randomly assigned to high-Ca fat-free milk session (HC) (equivalent to about three fat-free milk portions/d) or low-Ca control session (LC) session in 1:1 ratio. Participants and data analysts were blinded. An energy-restricted diet (restriction of $2092 \mathrm{~kJ} / \mathrm{d}$ ) containing $800 \mathrm{mg}$ of dietary $\mathrm{Ca} / \mathrm{d}$ was prescribed. Diets were prescribed according to the American Diabetes Association nutrition recommendations ${ }^{(1)}$ and considering the nutritional composition of the breakfast shakes provided during the study. Subjects commuted daily to the laboratory, where they consumed a breakfast shake containing $700 \mathrm{mg}$ (HC) (equivalent to approximately three servings of fat-free milk) or $6.4 \mathrm{mg}$ (LC) of Ca. A complete description of the nutritional composition of these shakes can be seen elsewhere ${ }^{(24)}$. All other meals were consumed in free-living condition in both sessions. Subjects were instructed to maintain constant PAL and medication use during the study. HC- and LCprescribed diets presented similar contents of macronutrients, vitamin $\mathrm{D}, \mathrm{P}, \mathrm{Mg}$, Zn and dietary fibre. HC-prescribed diet contained $1500 \mathrm{mg}$ and $\mathrm{LC}$ had $800 \mathrm{mg}$ of $\mathrm{Ca} / \mathrm{d}$.

Our breakfast shakes contained $17 \cdot 1 \pm 0.2 \mathrm{~g}$ of protein. HC shakes contained $20 \%$ casein and $80 \%$ whey protein, while LC shakes contained $100 \%$ whey protein. We included only whey protein in the LC because micellar casein (as present in milk) could not be used since it contains $\mathrm{Ca}$ and hydrolysed casein is less bioavailable. In milk, about $30 \%$ of Ca exists as free ionic $\mathrm{Ca}$ and the remaining approximately $70 \%$ is complexed with casein in micellar calcium phosphate. Besides, hydrolysed casein coagulates in the stomach, being less available for enzymatic hydrolysis and less absorbed in the intestine.

PAL, food intake, body composition (fat mass (FM) and fat-free mass), anthropometric (BW, waist circumference (WC), waist:hip ratio) and biochemical variables (serum $\mathrm{Ca}, \mathrm{P}, \mathrm{Mg}$, glucose, uric acid, HbA1c, vitamin D, insulin, fructosamine and parathormone (PTH) concentrations) were evaluated at baseline and after 12 weeks of each dietary experimental session.

\section{Physical activity assessment}

PAL was assessed at baseline and after 12 weeks of each experimental session using the long format International Physical Activity Questionnaire, version 6, validated for the Brazilian adult population ${ }^{(22)}$.

\section{Food intake assessment}

Food intake was assessed at baseline and after 12 weeks of each experimental session by $3 \mathrm{~d}$ dietary records. The amounts of foods were converted into grams for energy intake, macronutrients, $\mathrm{Ca}, \mathrm{P}, \mathrm{Mg}, \mathrm{Zn}$ and dietary fibre intake analyses using DietPro, version 5.1i (July 2015).

\section{Breakfast shakes}

HC and LC shakes presented similar macronutrients, vitamin D, $\mathrm{Na}$ and dietary fibre contents, differing mainly in Ca content. Ingredients and nutrient composition of the two shakes have been published elsewhere ${ }^{(24)}$. HC shakes contained fat-free milk powder (Itambé $®$ enriched with Fe; vitamins A, C and D; and Ca) reconstituted in water $(250 \mathrm{ml})$. To ensure similarity to $\mathrm{HC}$ shakes, LC shakes contained whey protein (BemVital®, Diacom), sucrose, sodium chloride (Cisne $®$ ) and a powder supplement containing Fe (iron chelate) and vitamins A (retinol acetate), $\mathrm{C}$ (ascorbic acid) and $\mathrm{D}_{3}$ (cholecalciferol).

\section{Anthropometric and body composition measurements}

BW was assessed using an electronic platform scale (Model 2096 PP) with a capacity for $150 \mathrm{~kg}$ and precision of $50 \mathrm{~g}$. Height was measured using a stadiometer with a scale of $0-220 \mathrm{~cm}$, precision $0 \cdot 1 \mathrm{~cm}$ (SECA 206, Seca). WC and hip circumferences were measured using a flexible inelastic tape. WC was measured at the 
midpoint between the lowest rib and the iliac crest with a precision of $0.1 \mathrm{~cm}$, and hip circumference was measured at the greatest circumference between the anterior iliac crest and the greatest trochanter. Waist:hip ratio was calculated by dividing WC by hip circumference.

Body composition was assessed using a Prodigy densitometer (GE Lunar Medical Systems). Scans were analysed using EnCoreTM, version 13.5 .

\section{Biochemical assays}

Venous blood samples were obtained after $12 \mathrm{~h}$ of overnight fasting. Serum total $\mathrm{Ca}$ concentrations were assessed by the Caarsenazo III method (intra-assay and inter-assay CV of 0.9 and $1.5 \%$, respectively) (Mira Plus, Roche Diagnostic Systems). A colorimetric assay (Bioclin kit, Quibasa Basic Chemical Ltda) was used to measure P and Mg concentrations, with intra-assay and inter-assay CV of 2.7 and $2.5 \%$ for $\mathrm{P}$, and 1.2 and $1.3 \%$ for $\mathrm{Mg}$, respectively. PTH concentrations were measured using an electrochemiluminescence immunoassay (intra-assay and inter-assay CV of $2 \cdot 8$ and $3.3 \%$, respectively) (Elecsys Modular-E170, Roche Diagnostics Systems). 25-Hydroxivitamin D concentrations were determined using a chemiluminescent microparticle immunoassay (Architect i2000, Abbott Diagnostics), with intraassay and interassay CV of $5 \cdot 1$ and $7 \cdot 2 \%$, respectively. IR was calculated using the updated homeostatic model assessment of insulin resistance (HOMA2-IR) index, which considers a more accurate physiological basis to predict homeostatic response than the HOMA-IR index. The HOMA2 index estimates $\beta$-cell function (\% B) and insulin sensitivity (\% S), and it was obtained using HOMA Calculator, version 2.2.2, available at https://www. dtu.ox.ac.uk/homacalculator/.

Serum total Ca concentrations were assessed by the Caarsenazo III method (Mira Plus, Roche Diagnostic Systems). Serum $\mathrm{P}$ and $\mathrm{Mg}$ concentrations were measured using a colorimetric assay (Bioclin kit, Quibasa Basic Chemical Ltda). Serum PTH concentrations were measured using an electrochemiluminescence immunoassay (Elecsys Modular-E-170, Roche Diagnostics Systems). Serum 25-hydroxivitamin D concentrations were determined using a chemiluminescentmicroparticle immunoassay (Architect i2000, Abbott Diagnostics).

\section{Statistical analysis}

Statistical analyses were conducted using the Statistical Package for Social Sciences for Windows, version 20.0 (IBM). All variables' distribution normality was assessed according to the Shapiro-Wilk test at $5 \%$ significance. Variance homogeneity was tested using the Levene test. An independent-samples $t$ test was conducted to identify possible differences between the subjects that started with either HC $(n 7)$ or LC $(n 7)$ at baseline. To verify the efficacy of the washout period, a paired $t$ test was conducted between the initial baseline data and the post-washout baseline data. Baseline data were calculated before each intervention period. Once the efficacy of the washout period was verified, the initial baseline and post-washout baseline data were combined, and the final data from each study arm ( $n 14$ each for the two sessions) were combined. Then, data within sessions were analysed using the paired $t$ test or Wilcoxon rank sum test,
Table 1. Anthropometry, body composition and biochemical data at baseline and after 12 weeks in the high-calcium fat-free milk (HC) and low-calcium control (LC) experimental sessions ( $n$ 14)

(Mean values and standard deviations)

\begin{tabular}{|c|c|c|c|c|c|c|c|c|}
\hline \multirow[b]{3}{*}{ Variable } & \multicolumn{4}{|c|}{ HC phase } & \multicolumn{4}{|c|}{ LC phase } \\
\hline & \multicolumn{2}{|c|}{ Baseline } & \multicolumn{2}{|c|}{ Final } & \multicolumn{2}{|c|}{ Baseline } & \multicolumn{2}{|c|}{ Final } \\
\hline & Mean & SD & Mean & SD & Mean & SD & Mean & SD \\
\hline \multicolumn{9}{|c|}{ Anthropometry and body composition } \\
\hline $\mathrm{BW}(\mathrm{kg})$ & 78.5 & $14 \cdot 6$ & $73 \cdot 5^{\star}$ & $15 \cdot 8$ & $76 \cdot 1$ & $15 \cdot 2$ & $75 \cdot 9$ & $15 \cdot 5$ \\
\hline BMI $\left(\mathrm{kg} / \mathrm{m}^{2}\right)$ & $29 \cdot 9$ & 4.4 & $27 \cdot 9$ & 4.4 & $27 \cdot 9$ & $4 \cdot 4$ & $28 \cdot 9$ & $4 \cdot 8$ \\
\hline FM $(\%)$ & 35.8 & $6 \cdot 0$ & $33 \cdot 1^{*}$ & $6 \cdot 7$ & 32.4 & $6 \cdot 0$ & 33.6 & $6 \cdot 6$ \\
\hline FFM (\%) & $64 \cdot 2$ & $6 \cdot 0$ & $66 \cdot 9^{*}$ & $6 \cdot 7$ & $67 \cdot 6$ & $6 \cdot 0$ & 66.4 & $6 \cdot 6$ \\
\hline WC (cm) & $97 \cdot 0$ & $11 \cdot 1$ & $91.9^{*}$ & 11.7 & $93 \cdot 1$ & 11.7 & $93 \cdot 1$ & $12 \cdot 2$ \\
\hline WHR & 1.0 & 0.1 & 0.9 & 0.1 & 0.9 & 0.1 & 0.9 & 0.1 \\
\hline \multicolumn{9}{|l|}{ Biochemical data } \\
\hline $\begin{array}{l}\text { Uric acid } \\
(\mathrm{mg} / \mathrm{dl}) \dagger\end{array}$ & 3.6 & 0.9 & $3 \cdot 2^{*}$ & 0.8 & 3.0 & 0.6 & 3.5 & $1 \cdot 1$ \\
\hline $\begin{array}{l}\text { Fructosamine } \\
(\mu \mathrm{mol} / \mathrm{l})\end{array}$ & $284 \cdot 3$ & $48 \cdot 8$ & $268 \cdot 3$ & 35.6 & $286 \cdot 9$ & $59 \cdot 1$ & $296 \cdot 8$ & $42 \cdot 4$ \\
\hline $\begin{array}{l}\text { Fasting glucose } \\
(\mathrm{mg} / \mathrm{dl}) \dagger\end{array}$ & $131 \cdot 1$ & $42 \cdot 9$ & $123 \cdot 4$ & 39.6 & $123 \cdot 8$ & $41 \cdot 1$ & $150 \cdot 3$ & $59 \cdot 2$ \\
\hline HbA1c (\%) & $7 \cdot 1$ & 1.6 & $6 \cdot 4^{*}$ & $1 \cdot 1$ & $6 \cdot 4$ & $1 \cdot 2$ & 6.9 & 1.5 \\
\hline Insulin ( $\mu \mathrm{IU} / \mathrm{ml})$ & 8.6 & $3 \cdot 8$ & $9 \cdot 2$ & $5 \cdot 1$ & $7 \cdot 6$ & 3.5 & $8 \cdot 6$ & $4 \cdot 1$ \\
\hline HOMA2-\%B & $58 \cdot 7$ & $26 \cdot 2$ & $61.9^{*}$ & 35.0 & 62.5 & $33 \cdot 2$ & $45 \cdot 7$ & 27.9 \\
\hline HOMA2-\%S & $101 \cdot 6$ & $57 \cdot 8$ & $108 \cdot 8$ & $71 \cdot 1$ & $115 \cdot 2$ & $51 \cdot 7$ & $104 \cdot 2$ & $54 \cdot 3$ \\
\hline HOMA2-IR & $1 \cdot 2$ & 0.5 & 1.3 & 0.7 & 1.0 & 0.5 & $1 \cdot 2$ & 0.6 \\
\hline
\end{tabular}

BW, body weight; FM, fat mass; FFM, free-fat mass; WC, waist circumference; WHR, waist:hip ratio; $\mathrm{HbA} 1 \mathrm{c}$, glycated $\mathrm{Hb}$; HOMA2-\%B, homeostatic model assessment-2 $\beta$ cell function; HOMA2-\%S, HOMA-2 insulin sensitivity; HOMA2-IR, HOMA-2 of insulin resistance.

* Mean value was significantly different from baseline $(P<0.05)$. BW $(P=0.034), \mathrm{FM}(P$ $=0.008)$, FFM $(P=0.036)$, WC $(P=0.000)$, uric acid $(P=0.001), \mathrm{HbA1c}(P=0.000)$, HOMA2-\%B $(P=0.014)$. Calculated from paired $t$ test (or Wilcoxon rank sum test) for comparing baseline with the 12-week value in each experimental session.

† To convert uric acid in $\mathrm{mg} / \mathrm{dl}$ to to $\mu \mathrm{mol} / \mathrm{l}$, multiply by 59.48 . To convert glucose in $\mathrm{mg} / \mathrm{dl}$ to $\mathrm{mmol} / \mathrm{l}$, multiply by 0.0555 .

pairing results from the same individual before (baseline) and after (12 weeks) each dietary intervention (LC or HC session), considering $P$ values less than 0.05 as significant. Data on changes from the baseline over the 12 weeks of the intervention (deltas, i.e. the final value minus the baseline value) were compared between the sessions using the paired $t$ test or Wilcoxon rank sum test, with Bonferroni correction for multiple comparisons. The criterion of significance adopted was $P<0 \cdot 025$, two tailed.

\section{Results}

Food intake and Ca homeostasis markers result have been published elsewhere ${ }^{(23)}$. In short, $\mathrm{Ca}(P=0.000), \mathrm{P}(P=0.000), \mathrm{Mg}$ $(P=0.002)$ and fibre intake $(P=0.013)$ increased after HC and remained unchanged after LC. The Ca:P ratio was 0.49 and 0.66 at baseline, and 0.74 and 0.62 post-treatment for the HC and LC, respectively. Dietary fibre $(P=0 \cdot 001)$, Ca $(P=0.000)$ and $\mathrm{P}(P=0.000)$ intake increased after HC compared with LC. HC final serum 25-hydroxyvitamin D concentrations were higher $(P=0.001)$, and PTH concentrations were lower $(P=0.003)$ compared with baseline values. PTH ( $P=0.002)$ and $\mathrm{Mg}(P=0.015)$ decreased, whereas 25-hydroxyvitamin D increased $(P=0.000)$ in HC compared with LC. 
(a)

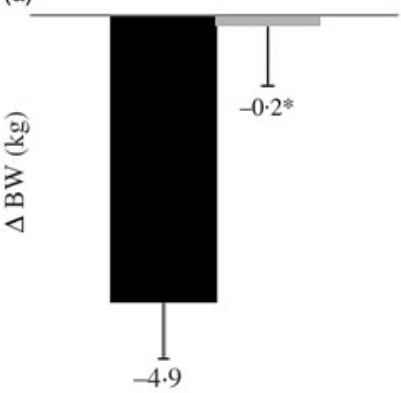

(c)

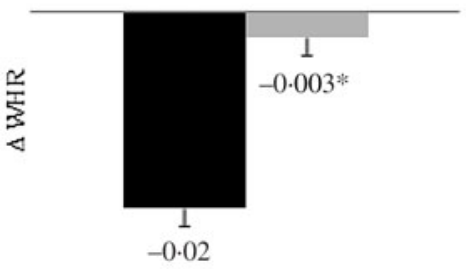

(b)

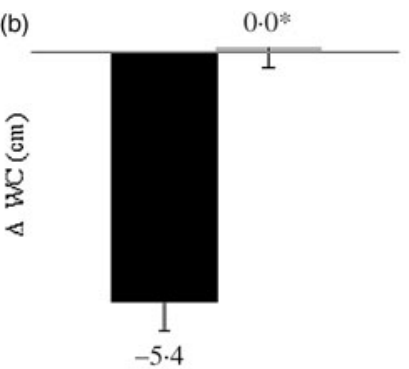

(d)

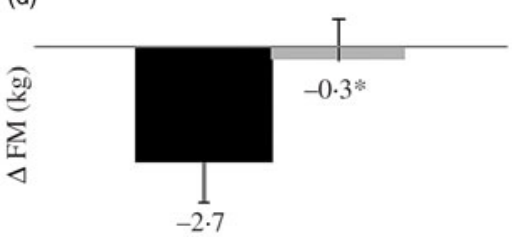

(e)

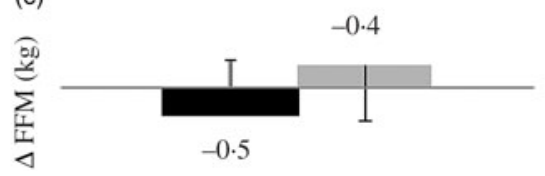

Fig. 1. Body weight (BW) (a), waist circumference (WC) (b), waist:hip ratio (WHR) (c), fat mass (FM) (d) and fat-free mass (FFM) (e) changes from baseline according to study session ( $n$ 14). During 12 consecutive weeks subjects consumed a high-calcium fat-free milk (700 mg of calcium/d; $-\mathbf{m})$ or a low-calcium control (6.4 mg of calcium/d; ) ) shake for breakfast. Energy-restricted diets (restriction of $2092 \mathrm{~kJ} / \mathrm{d}, 800 \mathrm{mg}$ of calcium/d) were prescribed. Values are means, with their standard errors represented by vertical bars. Except for FFM, all variables differed between sessions $\left({ }^{*} P<0.025\right.$, paired $t$ test with Bonferroni correction for multiple comparisons). BW $(P=0.019)$, FM $(P=0.000)$, WC $(P=0.000)$ and WHR $(P=0.004)$. Delta $(\Delta)$ was calculated subtracting the final value (after a 12-week intervention) from the baseline value.

\section{Anthropometry and body composition}

All the anthropometric variables and FM reduced after the HC session but did not change after the LC session compared with baseline (Table 1). HC promoted a greater reduction in BW, FM, WC and waist:hip ratio (Fig. 1). Percentage FM and WC decreased in HC, while it remained unchanged in LC (Table 1). Conversely, fat-free mass percentage increased in $\mathrm{HC}$ and remained unchanged in LC (Table 1).

\section{Glycaemic profile and calcium homeostasis}

HC final HOMA2-\%B was higher, and final serum uric acid and HbA1c concentrations were lower when compared with baseline values (Table 1). A comparison of changes over 12 weeks to the baseline (deltas) revealed that serum uric acid, fasting glucose and HbA1c decreased, whereas HOMA2-\%B increased in HC when compared with LC (Table 2).

\section{Discussion}

In the present study, the consumption of about three servings of fat-free milk and $1200 \mathrm{mg}$ of dietary $\mathrm{Ca} / \mathrm{d}$ (the amount consumed in the HC session) was more effective to control obesity (BW, FM and WC reduction), and the variables related to the glycaemic control (decrease in serum uric acid, HbA1c and fasting glucose and increase in HOMA2-\%B) than the control diet (low $\mathrm{Ca}$ consumption, approximately $525 \mathrm{mg} / \mathrm{d}$ ) in individuals with T2DM and low habitual $\mathrm{Ca}$ intake (less than $600 \mathrm{mg} / \mathrm{d}$ ). Possible mechanisms that explain our results are summarised in Fig. 2

Some authors reported that diets higher in dairy foods lead to beneficial effects on weight loss ${ }^{(8)}$, body fat ${ }^{(13,14,18)}$ and WC reduction $^{(13-15,18)}$, besides insulin sensitivity increase ${ }^{(25,26)}$, while others have observed no effects in these variables ${ }^{(9-12,17,27)}$. Methodological differences in these clinical trials can explain these controversial results, as described later.

First, the Ca dose $\left(1000^{(25)}\right.$ to $2400 \mathrm{mg}$ of $\left.\mathrm{Ca} / \mathrm{d}^{(9)}\right)$ and the supplementation period ( 6 weeks $^{(26)}$ to 1 year ${ }^{(10,25)}$ ) differed greatly between studies. However, the habitual Ca intake of the subjects seems to have more decisive effect in the results than the doses or the supplementation periods. Some authors did not report the subjects' habitual Ca intake ${ }^{(10,12)}$. In other cases, daily habitual Ca consumption was greater than or between 700 and $800 \mathrm{mg} / \mathrm{d}^{(9,11,17)}$. In these studies, no effect on adiposity or glycaemic profile was verified ${ }^{(9-12,17)}$. On the other hand, when habitual $\mathrm{Ca}$ intake at baseline was less than or between 600 and $700 \mathrm{mg} / \mathrm{d}$, beneficial effects on body composition and on insulin sensitivity were observed ${ }^{(8,13-15,18,25,26)}$. Zemel et al. ${ }^{(14)}$ emphasised the importance of selecting subjects with low 
Table 2. Biochemical data changes from baselinet in response to highcalcium fat-free milk $(\mathrm{HC})$ and low-calcium control experimental session (LC) $(n$ 14)

(Mean values and standard deviations)

\begin{tabular}{|c|c|c|c|c|}
\hline \multirow[b]{3}{*}{ Biochemical data } & \multicolumn{4}{|c|}{ Study phase } \\
\hline & \multicolumn{2}{|c|}{$\mathrm{HC}$} & \multicolumn{2}{|c|}{ LC } \\
\hline & Mean & SD & Mean & SD \\
\hline Uric acid (mg/dl) $\ddagger$ & -0.4 & 0.5 & $0.5^{\star}$ & 0.8 \\
\hline Fructosamine $(\mu \mathrm{mol} / \mathrm{l})$ & $-15 \cdot 1$ & $27 \cdot 9$ & $15 \cdot 3$ & $52 \cdot 4$ \\
\hline Fasting glucose $(\mathrm{mg} / \mathrm{dl}) \ddagger$ & -7.7 & $17 \cdot 6$ & $29 \cdot 3^{*}$ & 44.5 \\
\hline $\mathrm{Hb} 1 \mathrm{Ac}(\%)$ & -0.7 & 1.0 & $0.6^{*}$ & 0.7 \\
\hline Insulin $(\mu \mathrm{IU} / \mathrm{ml})$ & 0.7 & 4 & 0.9 & 3.4 \\
\hline HOMA2-IR & 0.06 & 0.5 & 0.2 & 0.5 \\
\hline HOMА2-\%B & $7 \cdot 3$ & 23.9 & $-13 \cdot 8^{\star}$ & $34 \cdot 1$ \\
\hline HOMA2-\%S & $10 \cdot 9$ & 55 & $-13 \cdot 1$ & 33.1 \\
\hline
\end{tabular}

$\mathrm{HbA} 1 \mathrm{c}$, glycated $\mathrm{Hb}$; HOMA2-IR, homeostasis model assessment-2 of insulin resistance; HOMA2-\%B, HOMA-2 $\beta$-cell function; HOMA2-\%S, HOMA-2 insulin sensitivity.

* $P<0.025$

† Changes from baseline were calculated by subtracting the final value from the baseline value. Uric acid $(P=0.008)$; fasting glucose $(P=0.020)$; Hb1Ac $(P=0.001)$; HOMA2-\%B $(P=0.016)$. $P$ value was estimated by paired $t$ test or Wilcoxon rank sum (both with Bonferroni correction for multiple comparisons).

$\ddagger$ To convert uric acid in $\mathrm{mg} / \mathrm{dl}$ to to $\mu \mathrm{mol} / \mathrm{l}$, multiply by 59.48 . To convert glucose in $\mathrm{mg} /$ dl to $\mathrm{mmol} / \mathrm{l}$, multiply by 0.0555 .

habitual intake of Ca (less than $600 \mathrm{mg} / \mathrm{d}$ ) for the benefits of increased $\mathrm{Ca}$ consumption to occur. Our subjects consumed 488.9 (sD 233.4) $\mathrm{mg}$ of $\mathrm{Ca} / \mathrm{d}$ at baseline (Table 1).

Furthermore, studies comparing the effects of a high intake of dairy products $v$. a control diet (low in dairy products) have showed significant BW and central fat reductions when subjects were concomitantly submitted to energy restriction ${ }^{(8,13,14,18)}$. The beneficial effects of increased $\mathrm{Ca}$ intake seem to be more significant when it is associated with moderate energy intake reduction ${ }^{(6,7)}$. However, in our study we observed that although the energy restriction prescribed was not followed by the subjects, the increased consumption of fat-free milk enhanced weight loss, improved body composition and promoted glycaemic control. Aside from that, consumption of low-fat dairy products seems to have more effect on T2DM control than the consumption of whole dairy products ${ }^{(5)}$. We and other authors have observed positive effects of Ca supplementation through low-fat dairy products on body composition and on glycaemic profile $^{(13,14,18,25,26)}$.

In most of the studies in which dairy Ca did not affect BW, adiposity and IR, habitual Ca intake was equal to or higher than $700 \mathrm{mg} / \mathrm{d}^{(9-12,17)}$. Although some authors tested the effect of energy restriction ${ }^{(9,11,12,17)}$ and/or of low-fat dairy consump$\operatorname{tion}^{(9,11,12)}$, the habitual Ca consumption seems to be the main determinant of the outcomes. Other features, such as the use of low vitamin $\mathrm{D}$ content dairy products ${ }^{(9)}$, lack of statistical power ${ }^{(11)}$ and intervention based only on nutritional counselling and using food records to assess food intake (since dairy product was not provided in the laboratory, there is no guarantee that the treatment was actually applied ${ }^{(10)}$, may also partially explain the lack of positive effects in some studies.

About $25-35 \%$ of the ingested $\mathrm{Ca}$ is absorbed in the intestine via paracellular (passive transport) and transcellular (active transport) pathways ${ }^{(28)}$. Transcellular Ca absorption is mediated by calcitriol and occurs mainly in duodenum and jejunum ${ }^{(28)}$. The rate of paracellular pathway is almost constant, while the transcellular pathway is more efficient under conditions of dietary Ca restriction ${ }^{(28)}$. Our participants were low habitual Ca consumers $(<600 \mathrm{mg} / \mathrm{d})$, so probably the transcellular $\mathrm{Ca}$ uptake increased when they consumed more $\mathrm{Ca}$ (HC session). So, adding three servings of fat-free milk per d (HC session) could be of interest in clinical practice, since Western diet is typically rich in $\mathrm{Na}$ and $\mathrm{P}$ (minerals that reduce $\mathrm{Ca}$ absorption), and poor in $\mathrm{Ca}$ and vitamin $\mathrm{D}^{(29)}$. However, the long-term effect of that is unknown, since the paracellular $\mathrm{Ca}$ absorption tends to increase under normal Ca consumption ${ }^{(28)}$.

Possible mechanisms involving Ca on weight loss and glycaemic control are not clear. It has been suggested that a low-Ca intake increases serum PTH and calcitriol (1,25-dihydroxyvitamin D), resulting in a $\mathrm{Ca}^{2+}$ influx into adipocytes via either receptor- or voltage-mediated $\mathrm{Ca}^{2+}$ channel activation ${ }^{(30)}$. High intracellular $\mathrm{Ca}^{2+}$ concentration stimulates fatty acid synthase gene expression, and consequently results in the stimulation of fatty acid synthase activity, increasing de novo lipogenesis ${ }^{(30)}$. In addition, elevated $\mathrm{Ca}^{2+}$ concentration inactivates Ca-dependent kinases and $\mathrm{Ca} /$ calmodulin-dependent protein kinase, which phosphorylate phosphodiesterase, resulting in reduced cAMP concentrations and, consequently, in inhibition of hormone-sensitive lipase ${ }^{(31)}$. Consequently, a low-Ca diet induces lipogenesis and inhibits lipolysis, leading to body fat accumulation and $\mathrm{IR}^{(30)}$. On the other hand, a high-Ca intake seems to reduce lipogenesis and promote lipolysis and increased thermogenesis, increasing fat oxidation and energy expenditure ${ }^{(30)}$. In our study, the breakfast shakes offered in both sessions contained $3.5 \mu \mathrm{g}$ of vitamin $\mathrm{D}$, which is about $20 \%$ of the recommendation for adults ${ }^{(3)}$. However, it seems that vitamin D from dairy shake $(\mathrm{HC})$ was more bioavailable than the vitamin $\mathrm{D}_{3}$ supplemented (LC), since serum vitamin D only increased in HC. The role of calcitriol in lipogenesis has been discussed. Concomitant supplementation of $\mathrm{Ca}$ and vitamin $\mathrm{D}$ increases the intestinal absorption of $\mathrm{Ca}^{(32)}$ and $\mathrm{BW}$ loss ${ }^{(2)}$. In adipocytes, vitamin D suppresses the differentiation of preadipocytes, reducing lipogenesis $^{(32)}$. We observed a decrease in serum PTH and an increase in serum 25-hydroyvitamin D after HC, suggesting the occurrence of these mechanisms.

Our breakfast shakes contained $17 \cdot 1 \pm 0 \cdot 2 \mathrm{~g}$ of protein. However, HC shakes contained $20 \%$ casein and $80 \%$ whey protein, while LC shakes contained $100 \%$ whey protein. We included only whey protein in the LC because micellar casein (as present in milk) could not be used since it contains $\mathrm{Ca}^{(33)}$ and hydrolysed casein is less bioavailable ${ }^{(33)}$. In milk, about $30 \%$ of $\mathrm{Ca}$ exists as free ionic $\mathrm{Ca}$, and the remaining approximately $70 \%$ is complexed with casein in micellar calcium phosphate $^{(33)}$. Besides, hydrolysed casein coagulates in the stomach, being less available for enzymatic hydrolysis and less absorbed in the intestine ${ }^{(34)}$. Milk proteins and bioactive peptides have been associated with increased satiety, increased thermogenesis, muscle protein loss sparing and enhanced glycaemic control $^{(35)}$. Branched-chain amino acids, especially leucine, seem to increase body fat loss by increasing fat oxidation, stimulating muscle protein synthesis and thus reducing lean tissue loss ${ }^{(36)}$. Although casein and whey protein have similar amounts of 
Subjects with type 2 diabetes and low habitual Ca intake

Dietary intervention

$\uparrow$ Fat-free milk consumption

(about three servings/d for 12 weeks)

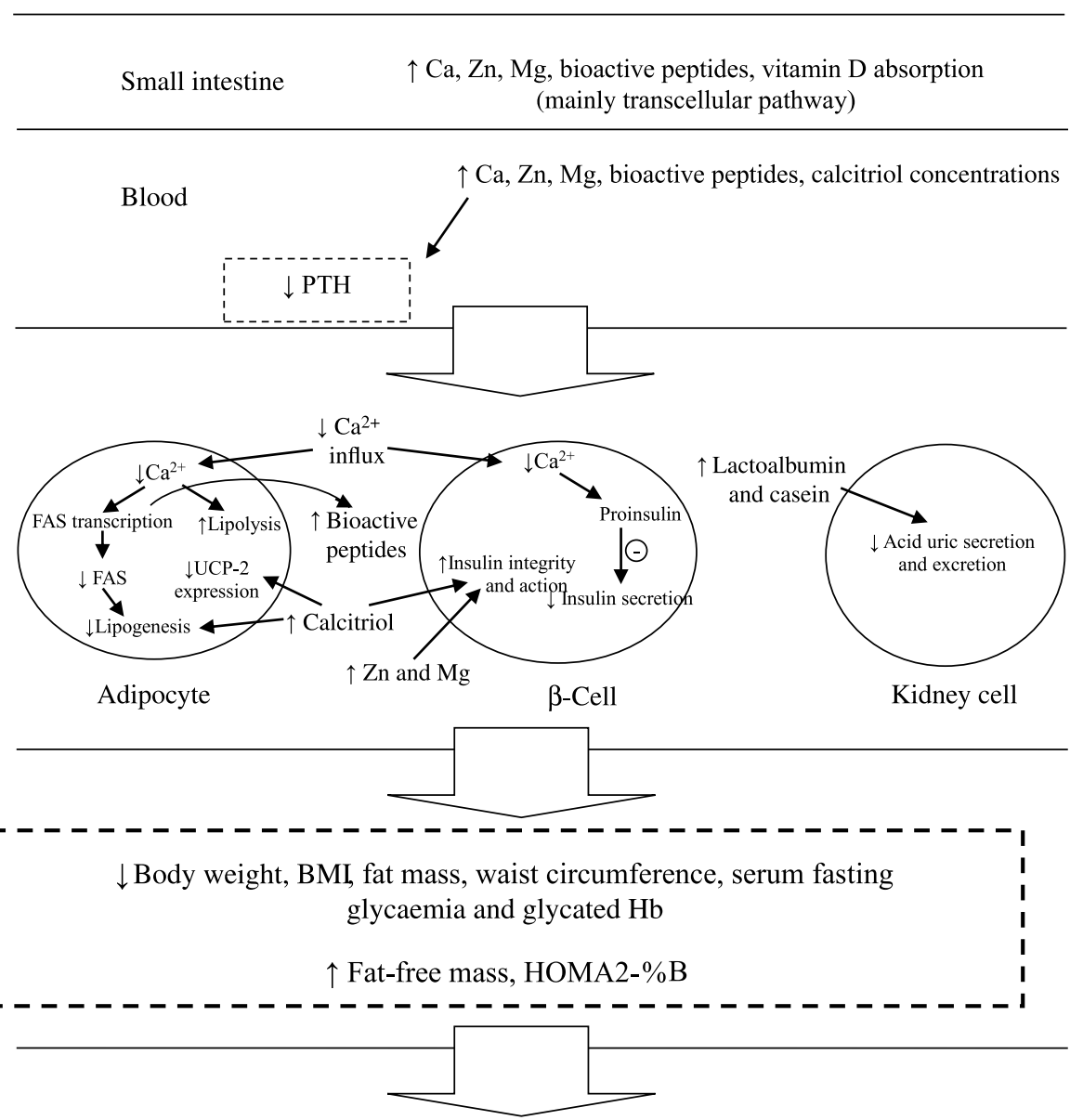

$\uparrow$ Type 2 diabetes and obesity control

Fig. 2. Possible mechanisms that explain the effects of increased fat-free milk consumption on diabetes and obesity control, based on our results. FAS, fatty acid synthase; HOMA2-\%B, homeostasis model assessment-2- $\beta$-cell function; PTH, parathormone; UCP-2, uncoupling protein 2.

leucine, when whey protein is ingested alone, its rapid intestinal transit reduces the absorption of branched-chain amino acid absorption $^{(36)}$. When whey protein is ingested with casein, which occurs naturally in milk protein, it increases intestinal transit time favouring the absorption of branched-chain amino acids $^{(36)}$. Therefore, in our study, the casein present in milk may have been essential to increase the uptake of leucine, which may have contributed to the lean tissue preservation and body fat reduction in $\mathrm{HC}$.

The effects of Ca on glycaemic control seem to be associated with insulin secretion, since Ca stimulates the conversion of proinsulin into insulin and promotes insulin release by the pancreatic $\beta$-cells ${ }^{(2)}$. Thus, an inadequate $\mathrm{Ca}$ intake may alter the balance between extracellular and intracellular $\beta$-cell Ca pools, which may interfere with the secretory function of pancreatic $\beta$ cells $^{(2)}$. In the present study, the increase in HOMA2-\%B suggests an increase in insulin secretion after HC session. HOMA2-\%B is considered the major contributor to the variability of $\mathrm{HbA} 1 \mathrm{c}$ in people with $\mathrm{T}_{2} \mathrm{DM}^{(37)}$. In addition, $\mathrm{HC}$ session decreased HbA1c concentrations compared with baseline and to LC session, improving our subjects' glycaemic control. This reduction can be due to the direct (i.e. stimulation of insulin secretion) and indirect (i.e. BW loss and reduction of FM) effects of Ca on insulin sensitivity. Other milk components, such as $\mathrm{Zn}, \mathrm{Mg}$ and vitamin $\mathrm{D}$, play a key role on insulin action. $\mathrm{Zn}$ is involved in insulin synthesis, storage and secretion as well as in insulin hexametric form 
conformational integrity ${ }^{(38)}$. Mg acts in insulin secretion and is a cofactor for multiple enzymes involved in carbohydrate metabolism ${ }^{(38)}$. In pancreatic $\beta$-cells, vitamin $\mathrm{D}$ activates the transcription of the insulin gene and the insulin receptor gene ${ }^{(32)}$. In addition, the presence of a vitamin $\mathrm{D}$ response element in the human insulin gene promoter suggests a potential influence of vitamin D on glucose homeostasis ${ }^{(32)}$. Therefore, our results cannot be attributed to dairy Ca only, as the synergistic effects of different components of fat-free dairy products may have influenced our results. The amount of $\mathrm{Ca}$ added to HC shakes (700 mg) was established bearing in mind the need to offer a relatively high load of $\mathrm{Ca}$ without affecting its applicability in clinical practice. These shakes were very well tolerated by the subjects. However, we cannot assure that the results obtained in the present study will be observed if instead of being consumed once that same amount of $\mathrm{Ca}$ was consumed in small amounts throughout the day.

We demonstrated that $\mathrm{HC}$ session reduced serum acid uric concentrations compared with baseline and with LC session. Milk proteins (lactalbumin and casein) have uricosuric effect ${ }^{(39)}$. In diabetic patients, serum acid uric has been considered an early marker of impaired glucose metabolism and a good predictor of cardiovascular risk ${ }^{(40)}$. Hyperglycaemia and hyperinsulinaemia resulting from IR decline renal function and increase uric acid production $^{(41)}$. Concomitantly, high serum uric acid concentrations inhibit insulin signalling and induce $\mathrm{IR}^{(42)}$. Uric acid also inhibits endothelial nitric oxide bioavailability and activates rennin-angiotensin system, resulting in renal dysfunction, hypertension and dyslipidaemia ${ }^{(41)}$. In our study, the HC session decreased HbA1c and increased HOMA2-\%B, suggesting that the attenuation of IR contributed to lower serum acid uric concentrations. Dietary fibre intake increased after the HC session. However, the recommendation for dietary fibre (14 g fibre/4184 $\mathrm{kJ})^{(43)}$ was achieved only in the HC session. The difference in dietary fibre between the experimental diets was approximately $9.4 \mathrm{~g} / \mathrm{d}$ after the interventions (24.6 (sD 4.8) $\mathrm{g} / \mathrm{d}$ in $\mathrm{HC}$ and $15.2(\mathrm{sD} 6.7) \mathrm{g} / \mathrm{d}$ in LC). An increase in fibre intake equivalent to $10 \mathrm{~g} / \mathrm{d}$ contributes to a weight loss of only $39 \mathrm{~g} / \mathrm{year}^{(44)}$ and the consumption of $42.5 \mathrm{~g}$ of fibre/d can affect glycaemic control $^{(45)}$, which refutes the possibility that fibre interfered in our results.

The low compliance to the dietary prescription is a limitation of the present study. This was a free-living study in which unfortunately it is not possible to strictly control the subjects' food consumption, although they have been carefully instructed. The small sample size of our study limited the statistical power to conduct a multivariate statistical analysis. However, the randomisation process was carefully conducted by us. Because of that, the intervention groups (HC and LC) presented similar baseline body composition, besides clinical, biochemical and anthropometric data.

We conclude that the consumption of about three servings of fat-free milk (700 mg of dietary additional $\mathrm{Ca} / \mathrm{d}$ ) and $1200 \mathrm{mg}$ of dietary $\mathrm{Ca} / \mathrm{d}$ for 12 weeks promoted greater weight loss and glycaemic control in individuals with T2DM and low-habitual $\mathrm{Ca}$ consumption $(<600 \mathrm{mg} / \mathrm{d})$ than did the low-Ca diet (approximately $525 \mathrm{mg} / \mathrm{d}$ ). These findings may be useful in the dietary treatment of T2DM.

\section{Acknowledgements}

We thank Instituto Federal do Sudeste de Minas (IF Sudeste MG), Coordenação de Aperfeiçoamento de Pessoal de Nível Superior (CAPES), Fundação de Amparo à Pesquisa do Estado de Minas Gerais (FAPEMIG), Conselho Nacional de Desenvolvimento Científico e Tecnológico (CNPq) and Bioclin, Quibasa Basic Chemical Ltda for the financial support.

J. M. G. G., J. A. C. and R. C. G. A. formulated the research question, designed the study, carried it out, analysed the data and wrote the article. P. V. M. R. assisted in the article writing.

The authors declare no conflicts of interest.

\section{References}

1. American Diabetes Association (2016) Standards of medical care in diabetes. Diabetes Care 39, Suppl. 1, S1-S2.

2. Pittas AG, Lau J, Hu FB, et al. (2007) The role of vitamin D and calcium in type 2 diabetes. A systematic review and meta-analysis. J Clin Endocrinol Metab 92, 2017-2029.

3. Institute of Medicine (2011) Dietary Reference Intakes for Calcium and Vitamin D. Washington, DC: The National Academies Press.

4. Pasin G \& Comerford KB (2015) Dairy foods and dairy proteins in the management of type 2 diabetes: a systematic review of the clinical evidence. Adv Nutr 6, 245-259.

5. Candido FG, Ton WTS \& Alfenas RCG (2013) Dairy products consumption versus type 2 diabetes prevention and treatment; a review of recent findings from human studies. Nutr Hosp $\mathbf{2 8}$, 1384-1395.

6. Abargouei AS, Janghorbani M, Salehi-Marzijarani $\mathrm{M}$, et al. (2012) Effect of dairy consumption on weight and body composition in adults: a systematic review and meta-analysis of randomized controlled clinical trials. Int J Obes 36, 1485-1493.

7. Stonehouse W, Wycherley T, Luscombe-Marsh N, et al. (2016) Dairy intake enhances body weight and composition changes during energy restriction in 18-50-year-old adults - a metaanalysis of randomized controlled trials. Nutrients $\mathbf{8}, 394$.

8. Zemel MB, Thompson W, Milstead A, et al. (2004) Calcium and dairy acceleration of weight and fat loss during energy restriction in obese adults. Obes Res 12, 582-590.

9. Bowen J, Noakes M \& Clifton PM (2005) Effect of calcium and dairy foods in high protein, energy-restricted diets on weight loss and metabolic parameters in overweight adults. Int $J$ Obes 29, 957-965.

10. Gunther CW, Legowski PA, Lyle RM, et al. (2005) Dairy products do not lead to alterations in body weight and fat mass in young women in a one year intervention. Am J Clin Nutr $\mathbf{8 1}$, 751-756.

11. Harvey-Berino J, Gold BC, Lauber R, et al. (2005) The impact of calcium and dairy product consumption on weight loss. Obes Res 13, 1720-1726.

12. Thompson WG, Holdman NR, Janzow DJ, et al. (2005) Effect of energy-reduced diets high in dairy products and fiber on weight loss in obese adults. Obes Res 13, 1344-1353.

13. Zemel MB, Richards J, Mathis S, et al. (2005) Dairy augmentation of total and central fat loss in obese subjects. Int JObes Relat Metab Disord 29, 391-397.

14. Zemel MB, Teegarden D, Loan MV, et al (2009) Dairy-rich diets augment fat loss on an energy-restricted diet: a multicenter trial. Nutrients 1, 83-100.

15. Stancliffe RA, Thorpe T \& Zemel MB (2011) Dairy attenuates oxidative and inflammatory stress in metabolic syndrome. Am J Clin Nutr 94, 422-430. 
16. Josse AR \& Phillips SM (2012) Impact of milk consumption and resistance training on body composition of female athletes. Med Sport Sci 59, 94-103.

17. Jones KW, Eller LK, Parnell JA, et al. (2013) Effect of a dairy- and calcium-rich diet on weight loss and appetite during energy restriction in overweight and obese adults: a randomized trial. Eur J Clin Nutr 67, 371-376.

18. Torres MR \& Sanjuliani AF (2013) Effects of weight loss from a high-calcium energy-reduced diet on biomarkers of inflammatory stress, fibrinolysis, and endothelial function in obese subjects. Nutrition 29, 143-151.

19. Devries MC \& Phillips SM (2015) Supplemental protein in support of muscle mass and health: advantage whey. JFood Sci $\mathbf{8 0}$, A8-A15.

20. Alberti KG, Eckel RH, Grundy SM, et al. (2009) Harmonizing the metabolic syndrome: a joint interim statement of the International Diabetes Federation Task Force on Epidemiology and Prevention; National Heart, Lung, and Blood Institute; American Heart Association, World Heart Federation, International Atherosclerosis Society; and International Association for the Study of Obesity. Circulation 120, 1640-1645.

21. Stunkard AJ \& Messick S (1985) The three-factor eating questionnaire to measure dietary restraint, disinhibition and hunger. J Psychosom Res 29, 71-83.

22. Pardini R, Matsudo S, Araujo T, et al. (2001) Validation of the International Physical Activity Questionnaire (IPAQ version 6): pilot study in Brazilian young adults. Rev Bras Cien Mov 9, $45-51$.

23. Mera R, Thompson H \& Prasad C (1998) How to calculate sample size for an experiment: a case-based description. Nutr Neurosci 1, 87-91.

24. Gomes JMG, Costa JA \& Alfenas RCG (2018) Effect of increased calcium consumption from fat-free milk in an energy restricted diet on metabolic syndrome and cardiometabolic outcomes in adults with type 2 diabetes mellitus: a randomized crossover clinical Trial. BrJ Nutr 119, 422-430.

25. Rideout TC, Marinangeli CP, Martin H, et al. (2013) Consumption of low-fat dairy foods for 6 months improves insulin resistance without adversely affecting lipids or bodyweight in healthy adults: a randomized free-living cross-over study. Nutr J 12, 56.

26. Maki KC, Nieman KM, Schild AL, et al. (2015) Sugar-sweetened product consumption alters glucose homeostasis compared with dairy product consumption in men and women at risk of type 2 diabetes mellitus. J Nutr 145, 459-466.

27. Shalileh M, Shidfar F, Haghani H, et al. (2010) The influence of calcium supplement on body composition, weight loss and insulin resistance in obese adults receiving low calorie diet. J Res Med Sci 15, 191-201.

28. Kopic S \& Geibel JP (2013) Gastric acid, calcium absorption, and their impact on bone health. Physiological Reviews 93 , 189-268.
29. Calvo MS \& Tucker KL (2013) Is phosphorus intake that exceeds dietary requirements a risk factor in bone health? Ann NY Acad Sci 1301, 29-35.

30. Zemel MB, Shi H, Greer B, et al. (2000) Regulation of adiposity by dietary calcium. FASEB J 14, 1132-1138.

31. Larsson S, Jones HA, Göransson O, et al. (2016) Parathyroid hormone induces adipocyte lipolysis via PKA-mediated phosphorylation of hormone-sensitive lipase. Cell Signal 28, 204-213.

32. Candido FG \& Bressan J (2014) Vitamin D: link between osteoporosis, obesity, and diabetes? Int J Mol Sci 15, 6569-6591.

33. Gaucheron F (2005) The minerals of milk. Reprod Nutr Dev $\mathbf{4 5}$, 473-483.

34. Dugan CE \& Fernandez ML (2014) Effects of dairy on metabolic syndrome parameters: a review. Yale J Biol Med 87, 135-147.

35. Acheson KJ, Blondel-Lubrano A, Oguey-Araymon S, et al. (2011) Protein choices targeting thermogenesis and metabolism. Am J Clin Nutr 93, 525-534.

36. Sun $X \&$ Zemel MB (2007) Leucine and calcium regulate fat metabolism and energy partitioning in murine adipocytes and muscle cells. Lipidis $\mathbf{4 2}, 297-305$.

37. Monnier L, Colette C, Thuan JF, et al. (2006) Insulin secretion and sensitivity as determinants of HbA1c in type 2 diabetes. Eur J Clin Invest 36, 231-235.

38. Yahya H, Yahya KM \& Saqib A (2011) Minerals and type 2 diabetes mellitus-level of zinc, magnesium and chromium in diabetic and non diabetic population. J Univer Med Dent College 2, 34-38.

39. Ghadirian P, Shatenstein B, Verdy M, et al. (1995) The influence of dairy products on plasma uric acid in women. Eur $J$ Epidemiol 11, 275-281.

40. Verdoia M, Barbieri L, Schaffer A, et al. (2014) Impact of diabetes on uric acid and its relationship with the extent of coronary artery disease and platelet aggregation: a single-centre cohort study. Metabolism 63, 640-646.

41. Neupane S, Dubey RK, Gautam N, et al. (2016) Association between serum uric acid, urinary albumin excretion, and glycated hemoglobin in type 2 diabetic patient. Niger Med J 57, $119-123$.

42. Zhu Y, Hu Y, Huang T, et al. (2014) High uric acid directly inhibits insulin signalling and induces insulin resistance. Biochem Biophys Res Commun 447, 707-714.

43. American Diabetes Association (2015) Standards of medical care in diabetes. Diabetes Care 38, S11-S94.

44. Du H, Van der ADL, Boshuizen HC, et al (2010) Dietary fiber and subsequent changes in body weight and waist circumference in European men and women. Am J Clin Nutr 91, 329-336.

45. Silva FM, Kramer CK, de Almeida JC, et al. (2013) Fiber intake and glycemic control in patients with type 2 diabetes mellitus: a systematic review with meta-analysis of randomized controlled trials. Nutr Rev 71, 790-801. 